\title{
Expression of cathepsin D and E-cadherin in primary laryngeal cancers correlation with neck lymph node involvement
}

\author{
Mustafa Paksoy $\cdot$ Umit Hardal · Cakır Caglar
}

Received: 14 June 2011 / Accepted: 5 July 2011 / Published online: 26 July 2011

(C) The Author(s) 2011. This article is published with open access at Springerlink.com

\begin{abstract}
Objective The aim of this study was to investigate the relation between Cathepsin D (Cath-D) and E-Cadherin (E-Cad) expression levels in tumor tissue and neck lymph node metastasis. This attempt should be made to identify new factors that one could be useful in predicting clinical behavior.

Study design In this study, we investigated rates of dying for E-Cad and Cath-D in paraphin blocks of larynx and neck dissection specimens taken from 56 selected patients. Laryngeal specimens dyed by ECad and Cath-D immunohistochemically. Immunoreactivity classified for E-Cad as positive (75\% and above), reduced (25-75\%) and negative (below 25\%). Immunoreactivity classified for Cath-D:dye absorption rates higher than $50 \%$ evaluated positive and absorption rates lower than $50 \%$ evaluated negative. We compared the rates of dying for E-Cad and Cath-D groups to with or without neck lymph node metastasis in specimens.

Results Neck metastasis were found in $41 \%$ of patients, in $55.6 \%$ of patients, if the E-Cad was negative, $40.6 \%$ if it was reduced, $33.3 \%$ if it was positive in specimens. The neck metastasis was found in $35.4 \%$ of patients with CathD expression negative, while $75 \%$ of patients was found with Cath-D expression positive.

Conclusion Neck metastasis was found higher in E-Cad reduced group than positive group. Neck node metastasis was significantly higher in Cath-D positive group than Cath-D negative group. Cath-D and E-Cad essays may useful in identifying neck lymph node involvement. Cath-D expression levels are more in this predictive factor than
\end{abstract}

M. Paksoy $(\bowtie) \cdot$ U. Hardal · C. Caglar

Kartal Training and Research Hospital, Kartal, Turkey

e-mail: opdrmustafapaksoy@yahoo.com
E-Cad levels for possibility of neck lymph node metastasis in LSCC.

Keywords Cathepsin D · E-Cadherin - Lymph node metastasis $\cdot$ Laryngeal carcinoma

\section{Introduction}

Laryngeal carcinoma accounts for $2-3 \%$ of all annual diagnosed cancers in the world (Jemal et al. 2004). The prognostic clinical characterization of LSCC remains inadequate because the outcome may differ considerably in comparably staged and treated patients (Pera et al. 1986). Currently, in LSCC tumor, behaviors and applied treatments, according to TNM and histological staging system, have managed. But different results of treatments are taken at the same age, stage and localizations in resemble patients; it shows some insufficiency of these classifications. According to these findings, we decided to investigate new prognostic factors and some new revaluations in clinic assessment.

Exception of distant metastasis, the presence of cervical lymph node metastasis, is the single most adverse independent prognostic factor. It decreases the overall survival approximately $50 \%$ and decreases the survival of more than $50 \%$ if extra capsular expansion exists (Jemal et al. 2004; Johnson and Myers 1991; Richard et al. 1987). Certain cervical lymph node metastasis assessment is difficult in all patients (Johnson and Myers 1991; Richard et al. 1987; Moe et al. 1996). The probability of positive lymph node in neck specimens in patients has found 13, 7-37\% with nonpalpable lymph node by examination (N0) (Kirchner and Carter 2004). We need better methods that could identify clinical behavior to predict lymph node metastasis, invasion 
of cancer tissue and can be cured by the removal of the primary tumor with lymph node micro metastasis for addition of neck dissection (Harrison and Thawley 1987). This situation correlates with clinic-pathologic characteristics of the tumor (Schipper et al. 1994). Molecular membranous labeling in metastatic cells may be useful for illustration of lymph node metastasis (Richard et al. 1987; Schantz 1994). Currently, it is investigated that the prognostic values of many tumor markers in immunohistochemical and molecular techniques like proteases, oncogene products, peptide growth factors (EGF and EGFR) and their effect of tumor invasion and metastasis in LSCC (Almadori et al. 2005; Vignon et al. 1982).

Degradation of basal membrane is the first attack of the carcinoma cells. There are some proteases effecting these procedures (Johnson and Myers 1991). Cathepsin D (Cath-D) is a well-known ones found in 1980, an aspartyl endopeptidase that, apart from its involvement in tumor invasion as a proteolytic enzyme, secreted from cancer and stromal cells has also been demonstrated to have a mitogenic effect in vitro, which suggests that elevated Cath-D levels may be associated with abnormal cell growth and it plays a role in basal membrane digestion and break down (Vignon et al. 1982). Elevated Cath-D levels in tissue increases angiogenic secretions causes' neovascularization, increases the transport and invasion of tumor cells and metastasis takes place easily (Isola et al. 1993; Leto et al. 1992).

The other important factor of tumor invasion is the Cadherin, a cell-surface glycoprotein's that act as intercellular adhesion molecules through calcium-dependent binding, which mediate predominantly homotypic cellcell interactions and play a key role during morphogenesis, as well as in the maintenance of the differentiated phenotype. E-Cadherin (E-Cad) is expressed in the lower spinous and basal cell layer (Richard et al. 1987). It is also involved in the transduction of signals controlling various cellular events, including polarity, differentiation, growth and cell migration (Johnson and Myers 1991). Loss of or reduction in E-Cad protein expression has been associated with increased invasiveness, advanced $\mathrm{T}$ and $\mathrm{N}$ stages and unfavorable prognosis (Shinohara et al. 1998). Its expression protected in well-differentiated cancers, which maintain their cell-cell adhesiveness and are less invasive, but reduced in undifferentiated cancers, which have lost their cell-cell adhesion and show a strong invasive tendency (Lee 1996).

We investigated the relation of neck lymph node involvement and the stromal expression levels of the E-Cad which mediated intercellular adhesion in epithelium and Cath -D, which cause degradation of basal membrane by using immunohistochemical techniques in LSCC in this study. The prognostic implications of changes in expression levels of these two markers are compared and evaluated in relation to neck node metastasis.

\section{Patients and methods}

This study included 51 men and 5 women, a total of 56 patients aged from 38 to 85 years (mean age: 55.9 years), who were diagnosed and treated for LSCC. All patients has only one primer tumor and no one had received another treatment.

Their tumors were staged according to the TNM system of the International Union Against Cancer (IUAC 4th edition), after surgical resections. Early staged tumors like $\mathrm{T} 1$ treated without neck node dissection were excluded in this study.

Their surgical resection and neck node dissections were performed on patients with histological and existence or highly possible neck lesions with T2 or locally advanced stage T3-4 on surgical findings. The stage of patient's tumors in T classification was as follows: 22 patients with $\mathrm{T} 2,24$ patients with $\mathrm{T} 3,10$ patients with $\mathrm{T} 4$.

All Patient had 4 well-differentiated, 44 moderate and 8 less differentiated tumors. Two of the tumor localizations were glottosubglottic, 24 of them glottosupraglottic, 16 of them supraglottic, 14 of them transglottic.

All patients received neck dissections bilaterally. Totally 112 neck dissections were applied as to 9 radical, 33 functional, 2 type II modified radical and 68 selective neck dissections on the operations.

The paraffin blocks and pathologic materials were selected from surgical larynx and neck dissection specimens of the patients. Methastasis positive and negatives patients were determined in neck node dissection materiales. Neck node methastasis was found in 23 of patients as in 6 of them T2, 13 of them T3 and 4 of them T4.

Laryngeal specimens dyed specifically for E-Cad and Cath-D immunohistochemical dye differently. Patients classificated and compared to their specimens according to dye taken in rates and lymph node involvement.

Dying formation classified in three groups for E-Cad as immunoreactivity preserved or positive (75 and up\%), reduced (25-75\%) and negative (lower than 25\%).

Dying formation classified in two groups for Cath-D as dye absorption rates over $50 \%$ of the observation area evaluated a positive, Cath-D group lower than $50 \%$ of the observation area evaluated negative Cath-D groups.

We compared the rates of dying E-Cad and Cath-D groups to, with or without neck lymph node metastasis in specimens. The effectiveness of neck lymph node metastasis of E-Cad, which causes intercellular adhesion, and Cath-D, which causes degradation of basal membrane, evaluated together and differently for the lymph node 
involvement with comparing to TNM classification in the same study.

\section{Immunohistochemical study}

Tissue specimens were collected during surgery, and the formalin-fixed paraffin-embedded tissues were cut into $2 \mu \mathrm{m}$ sections and dried on capillary-gap glass slides. Two different immunohistochemical markers for studying twice, section adhesive glass slides were taken. After spoiled, excessive block solution without washing for primer antibody E-Cad (monoclonal Mouse Antihuman E-Cad: NCH-38 DakoCytomation- USA) or Cath-D (monoclonal Mouse Antihuman Cath- D: SCI 13148 Santa Cruz Biotechnology-USA) was dropped. Staining was done at room temperature, slides were placed for $2 \mathrm{~h}$ and then the samples were washed with PBS 3 times for $5 \mathrm{~min}$. E-Cad showed membranous labeling in all the cells in the lower half of the normal squamous epithelium used as a positive control. Hence, only this half was considered to give the staining score of the normal mucosa surrounding the tumor. Cath-D and E-Cad immunoreactivity images were acquired using an Olympus BX40 microscope, randomized, without clinic data and evaluated from two independent observers. Appropriate positive controls were used (normal laryngeal epithelium). Negative controls with an omission of the antiserum from the primary incubation were also included. Immunostaining was done only in tumor parenchymal and stromal cells (well staining) far away tissue damages and necrosis. Cath-D immunostaining analyses were done in epithelium cell reactions. The staining was predominantly membranous with some cytoplasmatic staining. A staining score was given based on the percentage of cells stained (0-100\%). A score was given for both the tumor and the surrounding normalappearing epithelium. Cath-D expression was classified in two groups as epitel, immunostaining rates higher than $50 \%$ and lower than $50 \%$ observing the surface of tumors area (Goussia et al. 1999) (Figs. 1, 2). If E-Cad expression were classified in three groups as epitel cells, immunostaining rates have shown $75 \%$ or more immunostaining were evaluated as preserved or positive; $25-75 \%$ reduced staining; lower than $25 \%$ evaluated negative staining of the cell in the observing the surface of tumors area (Liu et al. 1997) (Figs. 3, 4).

\section{Statistical analysis}

Statistical analysis was performed by SPSS (Statistical Package for Social Sciences) for Windows 11.5. Distribution of Cath-D and E-Cad levels according to clinic-pathological parameters was analyzed by chi-square tests, and it was given standard deviations presumed, categorical

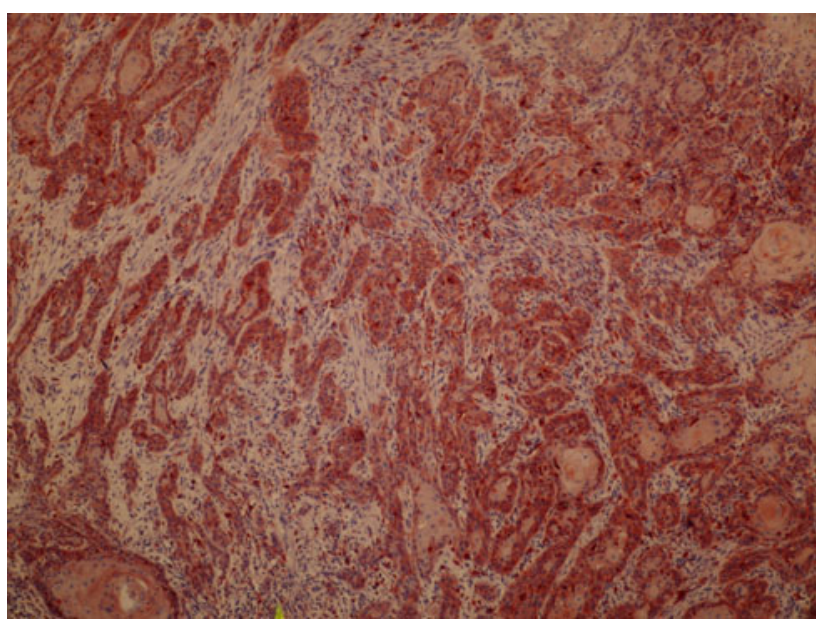

Fig. 1 Cathepsin D expression higher than $50 \%$ in case (magnification, $\times 40$ )

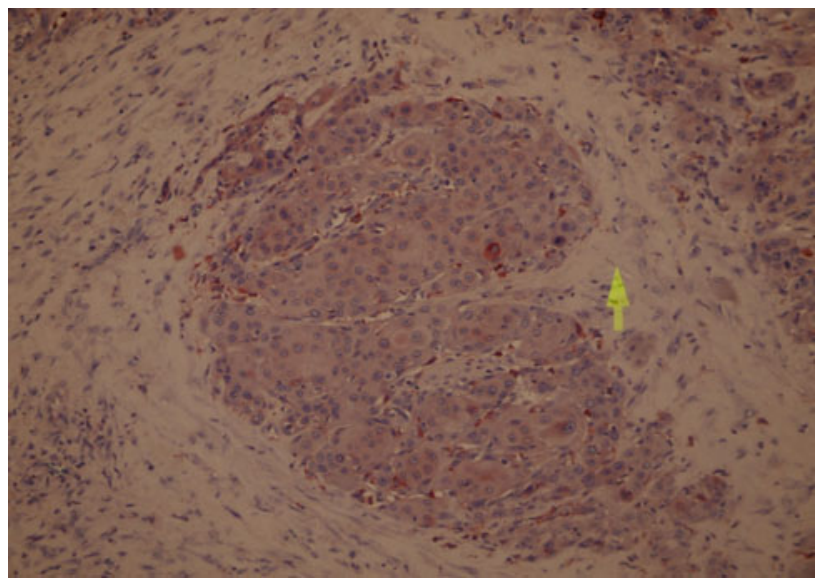

Fig. 2 Cathepsin D expression lower than $50 \%$ in case (magnification, $\times 40$ )

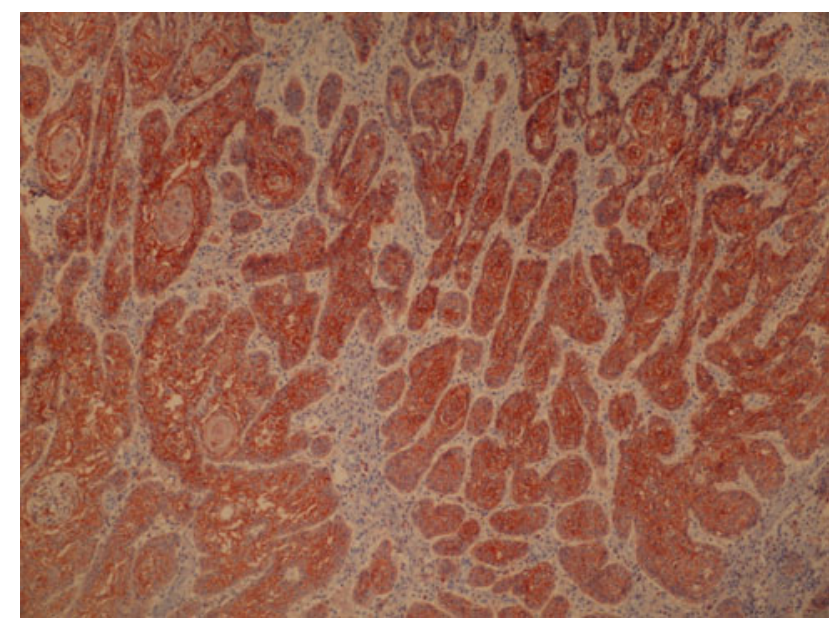

Fig. 3 Patients with tumors E-Cadherin immunoreactivity rates higher than $75 \%$ named protected (magnification, $\times 40$ )

changing parameters frequency and percents when evaluated study data of measurement changes, averaged, mean scores. 


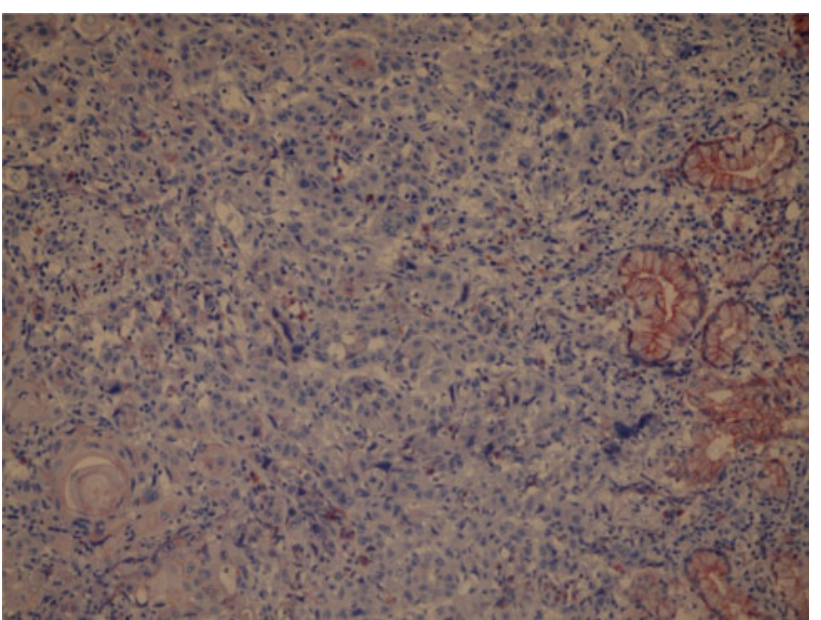

Fig. 4 Patients with tumors E-Cadherin immunoreactivity rates lower than $25 \%$ named negative (magnification, $\times 40$ )

Cath-D and E-Cad levels according to clinic-pathological parameters were analyzed by Pearson chi-square and Fisher's exact test. Staining scores were averaged for each group, and mean scores were compared within groups with respect to clinic-pathological parameters as the presence of cervical lymph node metastasis within the overall group.

To investigate whether a combination of parameters was more predictive for the nodal status than a single parameter, stepwise logistic regression analysis was performed using the variables that showed significant correlation with metastases in the univariate analysis.

Statistical significance was taken of $95 \%$ confidence intervals in the estimation of results, $P<0.05$. $P$ values of $<0.05$ were considered to be statistically significant.

\section{Results}

Forty-one percentage of the patients $(n=23 / 56)$ had clinically positive neck nodes in their therapeutic neck dissections specimens.

The stage of patients' tumors in TNM classification was: 22 patients $(39.3 \%)$ with $\mathrm{T} 2,24$ patients $(42.9 \%)$ with $\mathrm{T} 3$, 10 patients $(17.9 \%)$ with T4.

$\mathrm{T}$ stages of patients evaluated that the metastatic neck lymph node were found in $6 / 22(27.3 \%)$ of patients with $\mathrm{T} 2,13 / 24(54.2 \%)$ of patients with $\mathrm{T} 3,4 / 10(40 \%)$ of patients with $\mathrm{T} 4$.

Patients with Cath-D expression rate less than 50\% named negative group were found $85.7 \%$ of all and higher than $50 \%$ named positive group were found $14.3 \%$ of all.

The metastatic neck lymph nodes were found in $75 \%$ of patients if Cath-D expression was positive and $35.4 \%$ of patients if Cath-D expression was negative.
Table 1 The clinic-pathological features of the patients

\begin{tabular}{|c|c|c|c|c|}
\hline & \multicolumn{2}{|c|}{$\begin{array}{l}\text { Total } \\
(n=56)\end{array}$} & \multicolumn{2}{|c|}{$\begin{array}{l}\text { Neck node } \\
\text { metastasis }\end{array}$} \\
\hline & $n$ & $(\%)$ & $n$ & $(\%)$ \\
\hline $\mathrm{T} 1$ & - & - & - & - \\
\hline $\mathrm{T} 2$ & 22 & 39.3 & 6 & 27.3 \\
\hline $\mathrm{T} 3$ & 24 & 42.8 & 13 & 54.2 \\
\hline $\mathrm{T} 4$ & 10 & 17.9 & 4 & 40 \\
\hline Cath-D + (50\% and up $)$ & 8 & 14.3 & 6 & 75 \\
\hline Cath-D - (Lower than 50\%) & 48 & 85.7 & 17 & 35.4 \\
\hline E-Cath 25\% (negative) & 9 & 16.1 & 5 & 55.6 \\
\hline E-Cath 25-75\% (reduced) & 32 & 57.1 & 13 & 40.6 \\
\hline E-Cath $75 \%$ (protected) & 15 & 26.8 & 5 & 33.3 \\
\hline Cath-D + E-Cath 25\% & 2 & 3.6 & 2 & 100 \\
\hline Cath-D + E-Cath 25-75\% & 5 & 8.9 & 4 & 80 \\
\hline Cath-D + E-Cath 75\% & 1 & 1.8 & 0 & 0 \\
\hline Cath-D - E-Cath $25 \%$ & 7 & 12.5 & 3 & 42.9 \\
\hline Cath-D - E-Cath 25-75\% & 27 & 48.2 & 9 & 33.3 \\
\hline Cath-D - E-Cath $75 \%$ & 14 & 25 & 5 & 35.7 \\
\hline
\end{tabular}

The metastatic neck lymph nodes rates were found in patients according to Cathepsin D, E-Cadherin expression levels and T stages

Patients with tumors E-Cadherin immunoreactivity rates lower than $25 \%$ named negative were found $16.1 \%,(25-75 \%)$ named reduced $57.1 \%$, (75\%-up) named protected $26.8 \%$ of all, respectively.

Neck node metastasis was found positive in $55.6 \%$ of all if E-Cad was negative; $40.6 \%$ of all if E-Cad was reduced and $33.3 \%$ of all if E-Cad protected.

Cath-D expression levels positive and E-Cad levels negative were found in $3.6 \%$, reduced $8.9 \%$, protected $1.8 \%$ of all cases. Their neck node metastasis rates were found in 100,80 and $0 \%$ of all, respectively (Table 1 ).

Cath-D expression levels negative and E-Cad levels negative were found in $12.5 \%$ of all, reduced $48.2 \%$, protected $25 \%$ of all cases. Their neck node metastasis rates were found in $42.9,33.3$ and $35.7 \%$ of all, respectively (Figs. 5, 6).

Cath-D expression levels positive, E-Cad levels negative and $\mathrm{T} 4$ tumors were found as a prognosis deteriorating factors in LSCC. They were found 14.3, 16.1 and $17.9 \%$ of patients with LSCC, respectively. Their neck node metastasis rates were found $75,55.6$ and $40 \%$, respectively. This rates apparently high with the other groups. We can say that Cath-D expression levels positivity, E-Cad levels negativity and $\mathrm{T} 4$ tumors are as a prognosis deteriorating factors in LSCC.

E-Cad levels can determined or obviously effect neck metastasis rates. But the relation E-Cad expression and metastatic cervical lymph node were not found significant statistically (Fisher's Exact Test; $P=0.157$ ). 


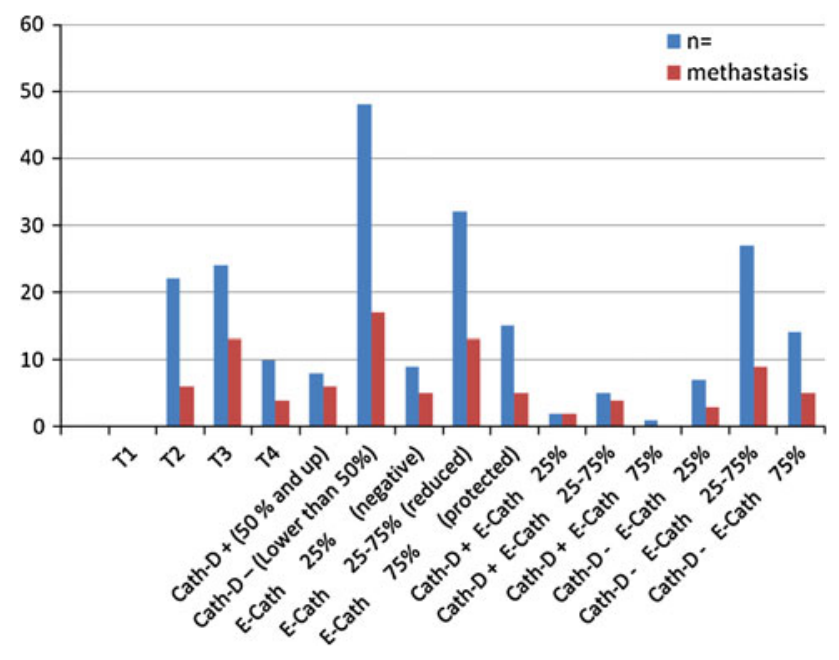

Fig. 5 The metastatic neck lymph nodes rates were found in patients according to Cathepsin D, E-Cadherin expression levels and T stages

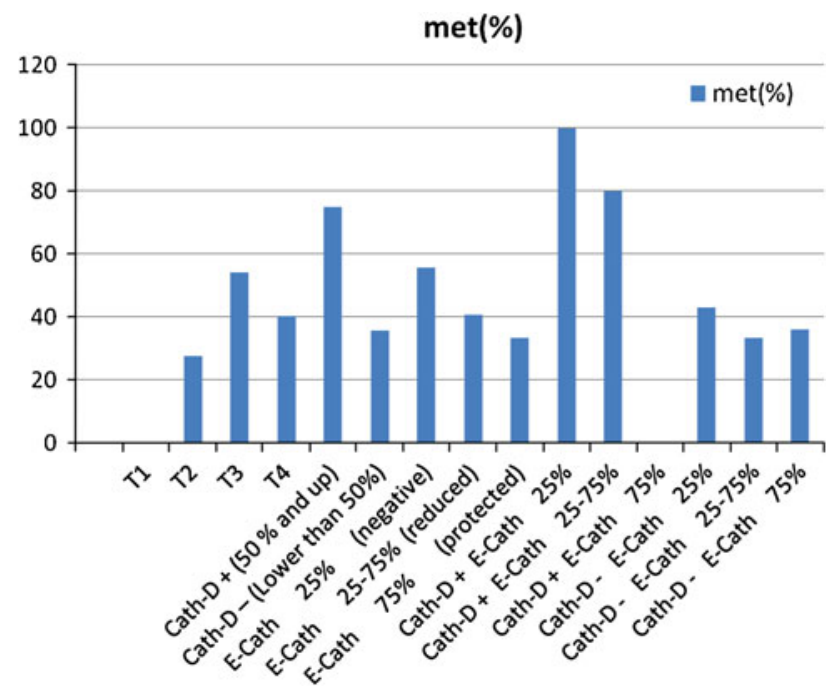

Fig. 6 The metastatic neck lymph nodes rates were found in patients according to Cathepsin D, E-Cadherin expression levels and T stages

Cath-D expression levels can determined or obviously effect neck metastasis rates.

We found a significant relationship between Cath-D rate, increasing and neck lymph node positivity $(\mathrm{N}+)$ at presentation (Fisher's Exact Test; $P=0.053$ ).

\section{Discussion}

The management of regional lymph nodes in the neck is important because of the decrease in the overall survival approximately 50\% (Andersen et al. 1994). With the exception of distant metastases, the presence of cervical lymph node metastasis is the single most adverse independent prognostic factor in the head and neck SCC (Suen and Stern 1996). Five-year survival is as $29-54 \%$ in $(\mathrm{N}+)$, but this is 65-94.5\% in N(0) patients (Cotran et al. 1994).

Palpation has been reported to detect about $70 \%$ of cervical metastasis in the clinical examination with palpation. In LSCC with clinically N0 neck probability of lymph node metastases is found 13.6-37\% in surgical specimens (Kirchner and Carter 2004; Takes et al. 1997). Molecular and immunohistochemical tumor markers help to determine cancer in risk bearing patients and areas of larynx mucosa. Cancer markers also show which drugs and targets we have to use in prophylactic treatment (Almadori et al. 2005). It is ideal to treat only the patients who had really occult metastases of the neck. Current technology is not compatible to determine for early occult metastasis without histopathological evaluation.

We investigated the effect of the immunohistochemical expression of E-Cad, which inhibits the tumor invasion and Cath-D, which provoked the tumor invasion on metastases of the neck in this study. It is possible that some patients with reduced E-Cad expression show subclinical cervical metastasis at the moment of diagnosis of the primary tumor, which would explain the association between this reduced expression and the higher incidence of regional relapses and disease free period (Shinohara et al. 1998).

Some studies have demonstrated a correlation between reduced E-Cad expression and nodal metastases tumor stage, grade of differentiation, invasiveness, lymph node involvement and distant metastases (Schipper et al. 1994; Bukholm et al. 1998; Lim et al. 2004). It was suggested that it was the best independent predictor of the appearance of cervical metastasis and found to be protected in well- and moderately differentiated cancers, but reduced or lost in undifferentiated cancers (Schipper et al. 1994; Shinohara et al. 1998).

Another investigators could not find any significant association between the degree of differentiation and E-Cad expression; however, they found that patients with reduced E-Cad expression in tumors showing higher invasiveness or cervical lymph node metastasis (Liu et al. 1997; Bagutti et al. 1998) and lost of the E-Cad expression in tumor cells in invasion area (Rodrigo et al. 2003) Chang et al. observed reduced E-Cad expression in $83 \%$ of their cases of carcinoma of the tongue. The prognosis in this subset of patients was significantly poorer than in the remaining patients (Chang et al. 2002). However, some studies have failed to show a relationship between E-Cad expression and these clinic-pathological variables (Takes et al. 1997; Bowie et al. 1993; Andrews et al. 1997).

We found $41 \%$ lymph node metastases in all cases. The E-Cad expression was found to reduce in $57.1 \%$ of cases and negative in $16.1 \%$ of cases, when added together in $73.2 \%$ of cases with LSCC. The significant association 
existed between E-Cad expression in the primary tumor and the presence of cervical metastasis, when reduced (40.6\%) and negative $(55.6 \%)$, in total reduced groups (43 9\%) compared to protected groups (33.3\%). However, it was not statistically significant. Analysis indicated and confirmed that reduced or absent E-Cad expression was associated with high relation with cervical lymph node metastasis. E-Cad expression may play a role in the decision to treat a NO neck with a neck dissection or with close follow-up (in addition to other factors like T-stage, histological differentiation, age and co-morbidity). These results were similar to those of Tanaka et al. 2003.

Cath-D expression was demonstrated in normal and cancerous tissues but more so dying in cancerous area compared to noncancerous area. Increasing of Cath-D expression not only specific for laryngeal tumors but also seen in ovarian, endometrial and breast carcinomas. The total concentration of Cath-D was a significant independent factor for identifying breast cancer patients with poor prognosis and at high risk of lymph node metastatic disease (Spyratos et al. 1989). There is not too much study on investigating Cath-D expression as immunohistochemical in laryngeal lesions. It has been known to effect this enzymes for lymph node but also it is not instutied any relation with the amount of Cath-D and lymph node metastasis (Lazaris et al. 2000). Andreas et al. suggested that the possibility involvement in the process of tumor spread but the concentrations of Cath-D did not correlate with survival, relapse-free survival for Cath-D immune status (Maurizi et al. 1996). Maurizi et al. have found a relation with increased Cath-D expression and recurrent laryngeal carcinoma and take role in tumor infiltration compared to other lesions. It has increased mainly in laryngeal CA compared to normal mucosa (Goussia et al. 1999). If it has found a higher rate in tumor tissue, it will be able to take a role in tumor metastasis (Maurizi et al. 1996). Hence they did not find a relation with clinic histopathological sign (TNM, recurrence, grade) (Smid et al. 1997).

We found increased Cath-D expression levels in $14.3 \%$ of case with LSCC. When it increased to $50 \%$ or higher, concentration of tissue associated with neck lymph node involvement at clinical presentation as $75 \%$. This finding suggests that Cath-D concentration is a significant independent prognostic factor for identifying LSCC patients at high risk of neck node metastasis. This is similar Diniz and Spyratos et al. findings, which was confirmed as a clear association between high cytosolic Cath-D and an increased metastatic potency of tumor cells of laryngeal cancer patients with a high risk of metastatic neck node involvement, similar to what happens in breast cancer (Spyratos et al. 1989; Diniz-Freitas et al. 2006).

Our results suggest that assessment of Cath-D and E-Cad status at the time of initial surgery may identify a subset of laryngeal cancer patients with increased metastatic potency and permit therapy to be adapted accordingly. Patients bearing tumors with high Cath-D and reduced E-Cad levels should undergo elective neck dissection, elective neck irradiation or post-surgical irradiation for neck lymph node metastasis even without extra nodal spread.

It shows that the risk of lymph node metastasis increases with Cath-D and reduced E-Cad values in a significant way. These data agree with the findings of Tandona et al. 1990 and Maudelonde et al. 1990.

\section{Conclusion}

Reduction in E-Cad expression and high Cath- D concentration in LSCC is a predictor for lymph node metastases. Together with other clinical and histological indicators, it can be considered a useful marker of poor prognosis in patients with LSCC.

Cath-D and E-Cad. expressions can determine at the first diagnostic biopsy in these patients. Their immunohistochemical determination might be useful in identifying patients with clinically negative lymph nodes. Assessment of Cath-D and E-Cad expression status at the time of initial surgery may identify a subset of laryngeal cancer patients with increased metastatic potency and therapy to be adapted accordingly.

Patients bearing tumors with high Cath-D and low E-Cad levels may carry a considerable risk for occult metastases and should undergo elective neck dissection or additional therapy. These two markers are a reliable indicator of increased tumor invasiveness in LSCC.

Further prospective trials are required to confirm the role of E-Cad and Cath- D expression in predicting the behavior of these neoplasms.

\section{Conflict of interest None.}

Open Access This article is distributed under the terms of the Creative Commons Attribution Noncommercial License which permits any noncommercial use, distribution, and reproduction in any medium, provided the original author(s) and source are credited.

\section{References}

Almadori G, Bussu F, Cadoni G, Galli J, Paludetti G, Maurizi M (2005) Molecular markers in laryngeal squamous cell carcinoma: towards an integrated clinicobiological approach. Review. Eur J Cancer 41(5):683-693

Andersen PE, Shah JP, Cambronero E, Spiro RH (1994) The role of comprehensive neck dissection with preservation of the spinal accessory nerve in the clinically positive neck. Am J Surg 168:499-502

Andrews NA, Jones AS, Helliwell TR, Kinsella AR (1997) Expression of the E-cadherin-catenin cell adhesion complex in primary 
squamous cell carcinomas of the head and neck and their nodal metastases. Br J Cancer 75:1474-1480

Bagutti C, Speight PM, Watt FM (1998) Comparison of integrin, cadherin, and catenin expression in squamous cell carcinomas of the oral cavity. J Pathol 186(1):8-16

Bowie GL, Caslin AW, Roland NJ, Field JKMA, Jones AS, Kinsella AR (1993) Expression of the cell-cell adhesion molecule E-cadherin in squamous cell carcinoma of the head and neck. Clin Otolaryngol 18:196-201

Bukholm K, Nesland JM, Karesen R, Jacobsen U, Borresen-Dale AL (1998) E-cadherin and alpha-, beta-, and gamma-catenin protein expression in relation to metastasis in human breast carcinoma. J Pathol 185:262-266

Chang HW, Chow V, Lam KY, Wei WI, Yuen A (2002) Loss of E-cadherin expression resulting from promoter hypermethylation in oral tongue carcinoma and its prognostic significance. Cancer 94(2):386-392

Cotran RS, Kumar V, Robbins SL (1994) Robbins pathologic basis of disease, 5th edn. WB Saunders, Philadelphia, pp 745-746

Diniz-Freitas M, García-Caballero T, Antúnez-López J, Gándara-Rey JM, García-García A (2006) Reduced E-cadherin expression is an indicator of unfavourable prognosis in oral squamous cell carcinoma. Oral Oncol 42(2): 190-200

Goussia A, Ioachim E, Peschos D, Assimakopoulos D, Vougiouklakis T, Skevas A, Agnantis N (1999) Immunohistochemical expression of cathepsin $\mathrm{D}$ in laryngeal epithelial lesions: correlation with CD44 expression, p53 and $\mathrm{Rb}$ status and proliferation associated indices. Anticancer Res 19(4B):3055-3060

Hahn SS, Spaulding CA, Kim JA, Constable WC (1987) The prognostic significance of lymph node involvement in pyriform sinus and supraglottic cancers. Int J Radiat Oncol Biol Phys 13:1143-1147

Harrison DFN, Thawley SE (1987) Surgical therapy of the larynx. In: Thawley SE, Panje WR (Eds) Comprehensive management of head and neck tumors, vol. II. WB Saunders, Philadelphia, pp 929-959

Isola J, Weitz S, Visakorpi T et al (1993) Cathepsin D expression detected by immunohistochemistry has independent prognostic value in axillary node-negative breast cancer. J Clin Oncol 11:36-43

Jemal A et al (2004) Cancer statistics. CA Cancer J Clin 54:8

Johnson JT, Myers EN (1991) Cervical lymph node disease in laryngeal cancer. In: Silver CE (ed) Laryngeal cancer. Thieme Medical Publishers, New York, pp 22-26

Kirchner JA, Carter D (2004) Pathology of the larynx. In: Mills SE (ed) Sternberg's diagnostic surgical pathology, vol. 2, 4th edn. Gopson Papers Ltd, Noida, India, pp 1007-1032

Lazaris A, Lendari I, Kavantzas N, Kandiloros D, Adamopoulos G, Davaris P (2000) Correlation of tumor markers p53, bel-2 and eathepsin-D with elinieopathologie features and disease-free survival in laryngeal squamous cell carcinoma pathology international 50:717-724

Lee SW (1996) H-cadherin, a novel growth inhibitory function and diminished expression in human breast cancer. Nature Med 2:776-782

Leto G, Gebbia N, Rausa L, Tuminello FM (1992) Cathepsin D in the malignant progression of neoplastic diseases (review). Anticancer Res 12(1):235-240

Lim SC, Zhang S, Ishii G et al (2004) Predictive markers for late cervical metastasis in stage I and II invasive squamous cell carcinoma of the oral tongue. Clin Cancer Res 10(1 Pt 1):166-172
Liu M, Lawson G, Delos M, Jamart J, Remacle M (1997) Expression of E-cadherin adhesion molecule in vocal cord carcinomas. Eur Arch Otorhinolaryngol 254:417-421

Maudelonde T, Martinez P, Laffargue F, Pages A, Rochefort H (1990) Cathepsin-D in human endometrium: induction by progesterone and potential value as a tumor marker. J Clin Endocrinol Metab 70(1):115-121

Maurizi M, Almadori G, Cadoni G et al (1996) Cathepsin D concentration in primary laryngeal cancer: correlation with clinico-pathological parameters, EGFR status and prognosis. Int $\mathbf{J}$ Cancer 69(2): 105-109

Moe K, Wolf GT, Fisher SG, Hong WK (1996) Regional metastasesin patients with advanced laryngeal cancer. Department of Veterans Affairs Laryngeal Cancer Study Group. Arch Otolaryngol Head Neck Surg 122:644-648

Pera E, Morena A, Galindo L (1986) Prognostic factors in laryngeal carcinoma. A multifactorial study of 416 cases. Cancer 58:928 934

Richard JM, Sancho-Garnier H, Micheau C, Saravane D, Cachin Y (1987) Prognostic factors in cervical lymph node metastasis in upper respiratory and digestive tract carcinomas: study of 1,713 cases during a 15-year period. Laryngoscope 97:97-101

Rodrigo JP, Dominguez F, Alvarez C, Herrero A, Suarez C (2003) Expression of E-cadherin, CD44s, and CD44v6 in laryngeal and pharyngeal carcinomas. Am J Otolaryngol 24(6):384-389

Schantz SP (1994) Head and neck oncology research. Curr Opin Oncol 6:265-271

Schipper JH, Unger A, Jahnke K (1994) E-cadherin as a functional marker of the differentiation and invasiveness of squamous cell carcinoma of the head and neck. Clin Otolaryngol 19:381-384

Shinohara M, Hiraki A, Ikebe T et al (1998) Immunohistochemical study of desmossomes in oral squamous cell carcinoma: correlation with citokeratin and E-cadherin staining, and with tumour behaviour. J Pathol 184(4):369-381

Smid L, Strojan P, Budihna M, Skrk J, Vrhovec I, Zargi M, Kos J (1997) Prognostic value of cathepsins B, D and steffins A and B in laryngeal carcinoma. Eur Arch Otorhinolaryngol 254(1):S150 S153

Spyratos M, Maudelondet F, Brouilletj P, Brunet M et al (1989) Cathepsin $\mathrm{D}$ an independent prognostic factor for metastasis of breast cancer. Lancet 8672:1115-1118

Suen JY, Stern SJ (1996) Cancer of the neck. In: Myers EN, Suen JY (eds) Cancer of the head and neck. WB Saunders, Philadelphia, pp 462-484

Takes RP, Baatenburg de Jong RJ, Schuuring E et al (1997) Markers for assesment of nodal metastasis in laryngeal carcinoma. Arch Otol Head Neck Surg 123:412-419

Tanaka N, Odajima T, Ogi K, Ikeda T, Satoh M (2003) Expression of E-cadherin, a-catenin, and b-catenin in the process oflymph node metastasis in oral squamous cell carcinoma. Br J Cancer 89(3):557-563

Tandona K, Clarkg M, Chamnesgs C, Chirgwinj M, Mcguirew L (1990) Cathepsin D and prognosis in breast cancer. New Engl J Med 322:297-302

Vignon F, Capony F, Chambon M, Freiss G, GarciaM, Rochefort H (1982) Autoendocrine erowth stimulation of the Mcf-7@. 7:185-192 